\title{
The Importance of Poultry in Environmental Dissemination of Cryptosporidium spp.
}

\author{
T.C.B. Bomfim ${ }^{*}, 1$, R.S. Gomes ${ }^{1}$, F. Huber ${ }^{2}$ and M.C.M. Couto ${ }^{1}$ \\ ${ }^{1}$ Universidade Federal Rural do Rio De Janeiro (UFRRJ) - Departamento De Parasitologia Animal, Instituto de \\ Veterinária, Brazil \\ ${ }^{2}$ Instituto Superior de Tecnologia de Paracambi (IST / FAETEC), Brazil
}

\begin{abstract}
The purpose of this study was to genotypically characterize and phylogenetically analyze the 18S rDNA sequences of Cryptosporidium obtained from poultry in Brazil. Fecal samples were obtained from ducks, chicks and quails sold in popular markets. DNA was isolated from Cryptosporidium positive feces, and 18S subunit rDNA was amplified and processed using nested-polymerase chain reaction (PCR). To identify the protozoan species, the PCR amplicons were used for restriction fragment length polymorphism (RFLP) and sequencing analyses. The presence of Cryptosporidium oocysts was observed in $76 \%$ of the ducks, $55 \%$ of the quails and $86 \%$ of the chicks. Sequencing and further phylogenetic analyses identified C. parvum in quails and chicks and C. baileyi in ducks. Although C. baileyi is usually a parasitic species found in birds, C. parvum, due to its weak host specificity, is the species most frequently diagnosed in various domestic and wild animal species, especially mammals. Thus, suggesting that the poultry observed in the present study would be considered as mechanical transporters of C. parvum, contributing to protozoa environmental dissemination.
\end{abstract}

Keywords: Cryptosporidium, poultry, occurrence, molecular diagnosis.

\section{INTRODUCTION}

Cryptosporidiosis is a parasitic disease prevalent in wild, domestic and captive birds from several parts of the world [1]. It has been reported in more than 30 species of birds from several orders such as Anseriformes, Chadriformes, Galliformes, Passeriformes, Psittaciformes and Struthiniformes [2-7].

Currently, three species of Cryptosporidium are considered to be bird parasites: Cryptosporidium baileyi [810] and until the moment there are 10 avian genotypes described [11]: avian genotype I-IV, black duck genotype, Eurasian Woodcock genotype and goose genotype I-IV [3, 7, 12-14]. In the future, these genotypes, combined with additional biological information, may be redescribed as species [15].

Studies have reported that in addition to the species and genotypes capable of infecting birds, there are other species and genotypes that are considered to be specific for their determined host, which would increase the number of hosts involved in the epidemiology of aviary cryptosporidiosis [12, 16]. Moreover, the low host specificity constitutes a risk factor for humans due to the zoonotic potential of some species, thus birds should be considered as a reservoir for human infection due to the possible mechanical transmission of C. parvum [13, 17-20].

*Address correspondence to this author at the Universidade Federal Rural do Rio De Janeiro (UFRRJ) - Departamento De Parasitologia Animal, Instituto de Veterinária, KM 7, BR 465, Seropédica/Rio de Janeiro, CEP: 23890-000, Brzil: Tel: 5521 26821617; E-mail: tcbb@ufrrj.br
In Brazil, some studies were conducted to evaluate Cryptosporidium infection in birds. The study of the occurrence of Cryptosporidium species in wild birds apprehended by environmental control agencies in São Paulo State, and demonstrated infection by C. galli, C. baileyi and the Avian genotype II [21]. In a study of exotic bird species [19], was diagnosed $C$. parvum infecting cockatiels; $C$. baileyi in a black vulture and a saffron finch; C. galli in canaries, a cockatiel, and lesser seed-finches; Cryptosporidium avian genotype I in a canary and an Indian peafowl; Cryptosporidium avian genotype II in ostriches and Cryptosporidium avian genotype III in a cockatiel and a peach-faced lovebird. Previous studies described C. baileyi infecting ducks and quails [22] and C. meleagridis infecting chicks [19, 22]. In exotic birds [23] described the infection with C. parvum in Bengalese finch and avian genotype III in Cockatiel and Java sparrow.

The aim of this study was to identify the species of Cryptosporidium in poultry sold in public markets in the state of Rio de Janeiro, Brazil.

\section{MATERIALS AND METHODS}

A total of 180 animals were purchased from public markets located in the city of Rio de Janeiro, Brazil. The markets were huge constructions with hundreds of different small stores, selling a great diversity of products, varying from food to electronics. Animal stores were near to some food (vegetables or meat) selling establishments or restaurants. The space for human circulation was usually very small and the contact between visitors, shoppers and animals was frequent. 
Generally, the animals were housed in piled up cages with overpopulation. Different kinds of animals were commercialized in the pet shops inside the markets, such as young poultry, little mammals (as puppies), guinea pigs, hamsters and rabbits. Besides the previously described animals, other mammals, such as young goats, could be observed being sold in some of those stores.

\section{Fecal Sample Collection and Processing}

A total of 180 birds were used in this study, which were acquired from two different markets (A and B). Thirty birds of each species were purchased from market A and the same amount was acquired from market B. The animals were divided into three groups, one for each animal species, and were composed of 60 chicks (Gallus gallus domesticus), 60 quails (Coturnix coturnix japonica) or 60 ducks (Anas platyrhynchos domesticus). The ducks and chicks studied were less than 30-days-old, and the quails were more than 30-days-old.

All the poultry were maintained in individual cages located in the Protozoology laboratory, until there was at least one fecal sample of each animal that could be submitted to coproparasitological analyses. The birds diagnosed as positive for Cryptosporidium spp. were maintained in the laboratory until the oocysts were no longer detected in their fecal samples for three consecutive analyses.

\section{Coproparasitological Examinations}

Coproparasitological examinations were carried out where fecal samples were weighed $(4 \mathrm{~g})$ and homogenized with $14 \mathrm{~mL}$ distilled water and filtered through plastic disposable sieves with an overlay of gauze. The filtered fecal material was then transferred to $15 \mathrm{ml}$ conical test tubes and centrifuged at $402 \times g$ for 10 minutes, and the supernatant was discarded. The precipitate was suspended in a saturated sugar solution (specific gravity $=1.3$ ), homogenized and centrifuged at $402.48 \mathrm{xg}$ for five minutes. The tube was then filled with a sugar solution and covered with a slide cover slip resting for three minutes. The cover slip was then mounted on a glass slide and examined under a microscope with and without phase contrast, using objectives at $40 \mathrm{x}$ and 100x magnification [24].

\section{Molecular Analysis}

Genomic DNA extractions were based on the protocols previously described in the literature [22, 23]. Nested-PCR was conducted in two amplification steps [25]. During the first step (i.e., the primary PCR), the following primers were used: 18 SF: 5'- TTCTAGAGCTAATACATGCG-3' (Forward) and 18 SR: 5' CCCATTTCC TTCGAAACAGG A-3` (Reverse) (expected amplicon size: 1,325 bp). During the second step (i.e. secondary PCR), the following primers were used: 18 SNF: 5`- GGAAGGGTTGTATTTATTAG ATAAAG-3' (Forward) and 18 SNR 5'-AAGG AGTAA GGAACAACCTCCA-3` (Reverse) (expected amplicon size: 819 to $865 \mathrm{bp}$, depending on the species). DNA extracted from oocysts obtained from calf feces was used as a positive control for DNA amplification during the primary and secondary PCR. Each positive sample was processed in duplicate, one for amplification of DNA for RFLP and another for sequencing.
The amplicon obtained in the nested-PCR was submitted to RFLP using two enzymes: SspI (Invitrogen ${ }^{\circledR}$ ) and VspI $\left(\right.$ Fermentas $\left.{ }^{\circledR}\right)$, following manufacturer's protocols. Digestion products electrophoresis was performed in 3\% agarose gel along with a $1 \mathrm{~Kb}$ plus DNA ladder (Invitrogen) molecular weight marker. The gel image was visualized and photographed using an image capture system (Bio-Rad ${ }^{\circledR}$ ). The program Quantity One $\left(\mathrm{Bio}^{-\mathrm{Rad}^{\circledR}}{ }^{\mathbb{B}}\right)$ was used to calculate the molecular weight of the obtained products. All the restriction patterns obtained were compared to those already reported in the literature [26].

The second Nested-PCR products for each sample were purified using the GFX Kit from GE healthcare ${ }^{\circledR}$, following the manufacturer's instructions. The purified amplicons were sent to the PDTIS/FIOCRUZ platform for quantification and sequencing using an automated 48-capilar 3730 sequencer, following laboratory protocols. Sequences were aligned and analyzed using MEGA version 4.1 and Bioedit softwares to obtain consensus sequences. The sequences were then used in a BLAST search (http://www.ncbi.mln-nih.goc/Genbank/ index.html) to determine their identity and to find homologous and similar sequences for each group of Cryptosporidium deposited in Genbank. Phylogenetic analyses were performed using the software MEGA version 4.1. Bootstrapping with 1000 replicates was used as a phylogenetic test, and a consensus tree was obtained using the neighbor-joining method, using the Kimura 2-parameter model. The sequences obtained were deposited in GenBank using the SeqIn computational program receiving accession numbers GU082384, GU082386, GU082387, GU082390 and GU082391.

Comparative phylogenetic analyses were carried out between the consensus sequences and the five first sequences listed during BLAST analysis. The following sequences deposited in GenBank were used: C. parvum: GU971622, GU971621, GU971620, GU971623, HQ009805, EF175936, EU553557, DQ833278, EU553550 and DQ656354, C. baileyi: GU816042, GU816039, GU816040, GU816041, GU816043. The following sequences deposited in GenBank were also used: C. meleagridis: EU827312, HM116384 and HM116383; avian genotype I: GQ227479; avian genotype II: DQ002931; avian genotype III: HM116386; avian genotype IV: DQ650344; Eurasian woodcock genotype: AY273769; duck genotype: AY504514; goose genotype I: AY120912; goose genotype II: AY504512; goose genotype III: AY324638; goose genotype IV: EF060289, C. galli: AY168848.

\section{RESULTS}

From the three species studied, $52(86,6 \%)$ chicks (Gallus gallus domesticus), 33 (55\%) quails (Coturnix coturnix japonica) and $46 \quad(76,6 \%)$ ducks (Anas platyrhynchos domesticus) were diagnosed as positive to Cryptosporidium spp.

In addition to their high occurrence, oocysts were also observed in large numbers in fecal samples ( $>30$ oocysts/field) collected from the same bird.

Morphometric measurements of the Cryptosporidium isolates present in feces of quails, chicks and ducks were conducted and are shown in Table $\mathbf{1}$. 
Table 1. Morphometric Means, Restriction Fragment Length Patterns and Sequencing Results of the Cryptosporidium Isolates Obtained from Poultry with Corresponding GenBank Accession Numbers

\begin{tabular}{|c|c|c|c|c|c|c|}
\hline Poultry & Species of Birds & $\begin{array}{c}\text { Average } \\
\text { Oocyst Size }\end{array}$ & Enzyme SspI & Enzyme VspI & $\begin{array}{c}\text { Genbank Access Numbers and } \\
\text { Sequence Size }\end{array}$ & Blast Results \\
\hline \hline $\begin{array}{c}\text { Chicks } \\
\text { I and II }\end{array}$ & $\begin{array}{c}\text { Gallus gallus } \\
\text { domesticus }\end{array}$ & $\begin{array}{c}5.8 \times 4.6 \mu \mathrm{m} \\
(\mathrm{n}=100)\end{array}$ & $465,265,100$ & 651,100 & $\begin{array}{c}\text { GU082390 (613 bp), } \\
\text { GU082391 (613 bp) }\end{array}$ & C.parvum \\
\hline $\begin{array}{c}\text { Quails } \\
\text { I and II }\end{array}$ & $\begin{array}{c}\text { Coturnix coturnix } \\
\text { japonica }\end{array}$ & $\begin{array}{c}6.1 \times 4.8 \mu \mathrm{m} \\
(\mathrm{n}=50)\end{array}$ & $465,268,102$ & 655,101 & $\begin{array}{c}\text { GU082384 (543 bp), } \\
\text { GU082386 (600 bp) }\end{array}$ & C.parvum \\
\hline Duck I & $\begin{array}{c}\text { Anas platyrhinchus } \\
\text { domesticus }\end{array}$ & $\begin{array}{c}6.0 \times 4,5 \mu \mathrm{m} \\
(\mathrm{n}=50)\end{array}$ & $\begin{array}{c}648,106^{*} \\
469,264^{*}\end{array}$ & 650,101 & GU082387 (532 bp) & C. baileyi \\
\hline
\end{tabular}

*Cutting pattern was inconclusive to define species.

$\mathrm{n}=$ number of measured oocysts.

$\mathrm{bp}=$ base pair.

Results from the DNA amplification reactions from secondary PCR showed bands with amplicons varying in length from 850 to $871 \mathrm{bp}$. The results of restriction fragment length patterns and sequencing of the Cryptosporidium isolates are shown in Table 1. Species identification of Cryptosporidium obtained in the present study was not possible through the observation of the fragments obtained with the use of restriction enzyme. Due to the lack of data to diagnose the species, the samples were sequenced using the Nested-PCR primers in both directions. All the 15 samples used in the RFLP were sequenced but only five of them presented good quality sequences.

When the sequences of the present study were submitted to BLAST search, the C. parvum species isolated from quails and chicks showed $99 \%$ sequence similarity with $C$. parvum sequences from human origin (GU971622, GU971621, GU971620 and GU971623), bovine origin (HQ009805 and EF175936), reptile origin (EU553557 and EU553550) and swine origin (DQ833278).

The Cryptosporidium sequence from duck shared high similarity, 99\%, with GenBank sequences from C. baileyi obtained from birds (GU816042, GU816039, GU816040, GU816041, and GU816043).

During phylogenetic analysis, the isolates obtained in this study grouped with previously described species as confirmed by the topology of the phylogenetic tree generated using the neighbor-joining method. The isolates from the chicks and quails grouped with $C$. parvum species, and the one duck isolate grouped with $C$. baileyi species.

Phylogenetic tree of the Cryptosporidium spp. isolated from poultry and those deposited in GenBank. Bootstrap 1000, Kimura 2 Paramether (Fig. 1). The phylogenetic tree suggests that the samples quail I and II; chick I and II are more related to $C$. parvum and the sample duck I presents more similarities to $C$. baileyi.

\section{DISCUSSION}

Worldwide, birds are considered as disseminators of many pathogens, being the genera Cryptosporidium one of the most important because it is diagnosed in a wide variety of them [1], where some of this coccidia species may have zoonotic potential [27].

Despite the importance of species characterization related to the epidemiology of avian cryptosporidiosis, there are few studies that have tried to identify this protozoan in poultry. Among those, there are reports of Cryptosporidium spp. in ducks [2, 17, 22, 28], chicks [22, 28, 29] and quails [12, 22].

The high rate of infection for domestic birds and the large number of oocysts found have been previously demonstrated in the literature. Bird management may also contribute to high infection rates. Other study [3] verified that low infection rates in birds could be related to efficient management of the aviaries observed. However, in this study, the sanitary conditions were characterized as poor due to the lack of periodical cleaning of the cages, overpopulation and different species of birds in the same cage. Besides that, the presence of small mammals in the pet shops, which could be infected with $C$. parvum, probably could have caused the spread of oocysts in the surroundings, favoring the ingestion by birds that might act as an environment disperser. Similar situation was described in Malaysia [20], suggesting that a huge variety of birds may be considered as mechanical transporters of $C$. parvum, favoring the infection to human and other mammals.

On the other hand, some studies have concluded that the high prevalence of parasitic infection is influenced by avian age. Because all the purchased birds, with exception of quails, were less than one month of age, their immune system could exhibit a low efficiency [30,31].

The high quantity of oocysts found in the feces of the birds ( $>30$ oocysts/field) allowed statistical morphometric analysis, however, due to morphometric similarities between the species, this technique did not allow for species identification. It was possible to make species identifications by combining these results with those obtained by molecular biology techniques.

Two species of Cryptosporidium were diagnosed from the studied birds, the first was $C$. baileyi, observed in the feces of an infected duck and the second was $C$. parvum, which was diagnosed from quails and chicks feces. The presence of $C$. baileyi was originally described in commercial broiler chickens and is usually found as a parasite in a large variety of birds hosts, including chicks, ducks, and quails $[3,4,8,9,12,13,22,28,32]$ agreeing with the results reported in this research. The presence of oocysts of $C$. parvum in feces of some birds observed in the present study agree with previous researches, where the authors suggested that the birds would be acting as mechanical 


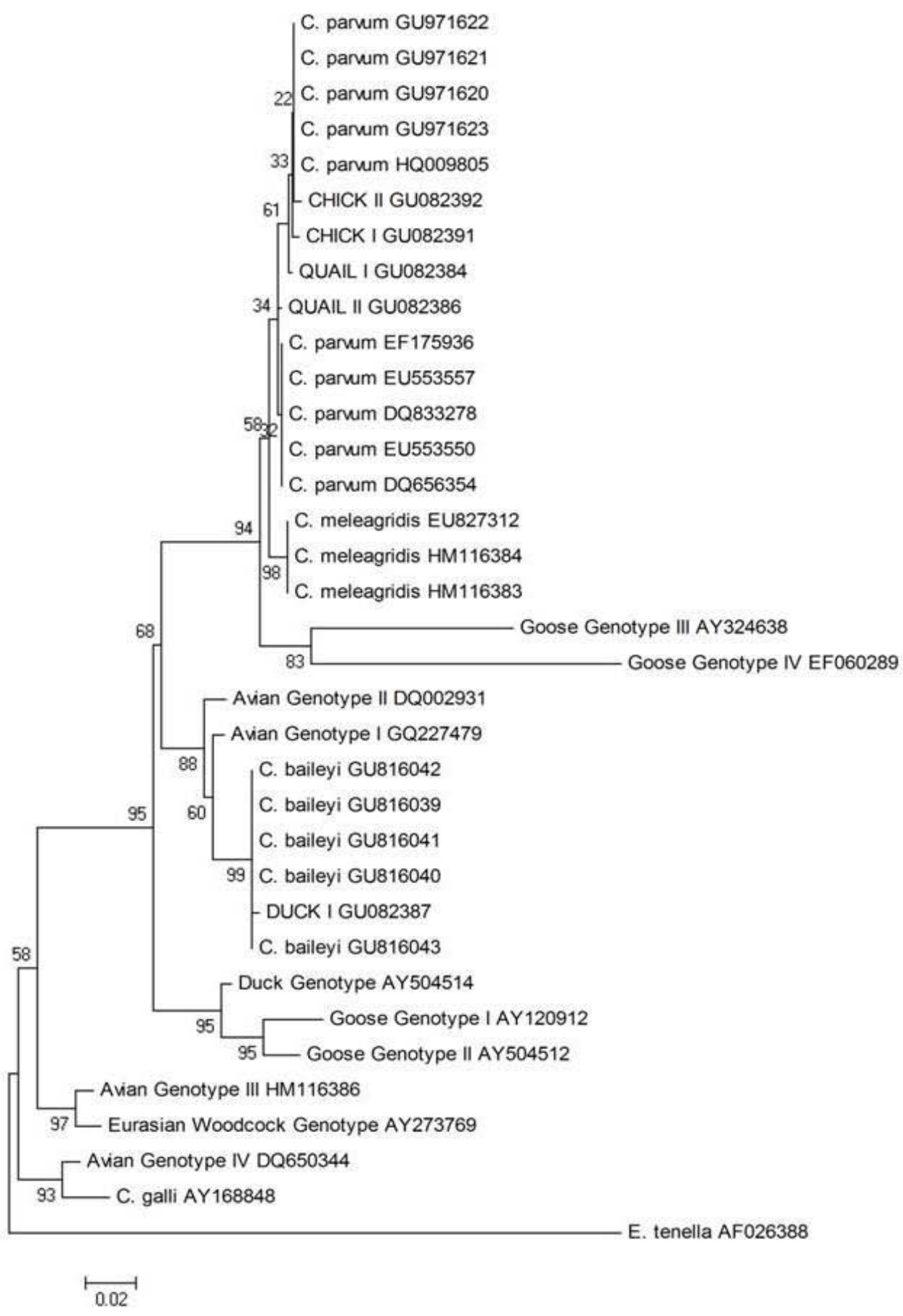

Fig. (1). Phylogenetic tree of the Brazilian Cryptosporidium species isolated from domestic birds and species already deposited in GenBank. The numbers represent bootstrap values for neighbor-joining. The samples obtained in this study and presented in the phylogenetic tree: Quail I - GU082384; Quail II - GU082386; Duck I - GU082387; Chick I - GU082391; Chick II- GU082392.

vectors, shedding oocysts in the environment, even if at a low rate $[18,19,33]$.

The diagnosis of Cryptosporidium in domestic chickens, ducks and quails is relevant because these animals are purchased and sold while young in order to maintain a small subsistence breeding program for egg and meat production within households. The introduction of animals shedding the infectious form of Cryptosporidium (which is easily disseminated on the environment) into a household is considered to be a risk factor of Cryptosporidium infection to other animals and humans.

An additional aspect that should be taken into consideration is the place where the birds were being sold. At these locations, in addition to other species of birds, there 
were small mammals that were kept in shelved cages, which allowed contact between species. Therefore, all the animals being sold were exposed to this environment, which increased their chances of being infected. These unhealthy conditions would probably put uninfected small mammals and birds at risk of being infected from positive birds of the same or different species.

The markets where these birds were purchased were very crowded with people looking to buy low-cost food products sold "in natura," such as fruits, vegetables, grains, etc. However, it was noticeable that in this environment, the close proximity of the stores favored a possible dissemination of the infectious form of Cryptosporidium.

The commercialization of very young birds is attractive to the young children that are commonly present in this environment. We frequently observed children petting ducks, chicks and quails. The ducks, chicks and quails could be purchased for these children and kept as pets inside households, becoming a risk for infection to humans of all ages.

The results obtained in the present study suggest that birds may be considered as mechanical transporters of $C$. parvum oocysts, besides that, the poultry studied were infected by $C$. baileyi which is cause of severe pathogenicity in these hosts.

\section{CONFLICT OF INTEREST}

The authors confirm that this article content has no conflict of interest.

\section{ACKNOWLEDGEMENTS}

We would like to thank the National Council for Scientific and Technological Development (CNPq) and the Research Foundation of the State of Rio de Janeiro (FAPERJ) for their financial support.

\section{REFERENCES}

[1] Sréter T, Varga I. Cryptosporidiosis in birds - A review. Vet Parasit 2000; 87: 261-79.

[2] Kuhn RC, Rock CM, Oshima KH. Ocurrence of Cryptosporidium and Giardia in wild ducks alongs the Rio Grande River Valley in Southern New Mexico. Appl Environ Microbiol 2002; 68: 161-5.

[3] Jellison KL, Distel DL, Hemond HF, Schauer DB. Phylogenetic analyses of the hypervariable region of the $18 \mathrm{~S} \mathrm{r}$ RNA gene of Cryptosporidium oocysts in feces of Canada Geese (Branta canadensis): Evidence for five novel genotypes. Appl Environ Microbiol 2004; 70(1): 452-8.

[4] Ryan UM, O'hara A, Xiu O. Molecular and biological characterization of a Cryptosporidium molnari-like isolate from a guppy (Poecilia reticulata). Appl Environ Microbiol 2004; 70: 3761-5.

[5] Kim Y, Howert EW, Shin NS, Knon SW, Terrell SP, Kim DY. Disseminated visceral coccidiosis and cloacal cryptosporidioseis in a Japanese white-naped crane (Grus vipio). J Parasitol 2005; 91: 199-201.

[6] Kwon YK, Wee SH, Kook JH, Lee CG. Outbreak of enteric cryptosporidiosis in cockatiels (Nymphicus hollandicus). Vet Res 2005; $12: 210-1$

[7] Meireles MV, Soares RM, Dos Santos MM, Gennari SM. Biological studies and molecular characterization of a Cryptosporidium isolate from ostriches (Struthio camelus). J Parasitol 2006; 92: 623-6.
[8] Current WL, Upton SJ, Haynes TB. The life cycle of Cryptosporidium baileyi, n. sp. (Apicomplexa: Cryptosporiidae) infecting chickens. J Protozool 1986; 33: 289.

[9] Slavin D. Cryptosporidium meleagridis. J Comp Pathol 1955; 65: 262-6.

[10] Ryan UM, Xiao L, Read C, et al. A redescription of Cryptosporidium galli, Pavlasek, 1999 (Apicomplexa: Cryptosporidiidae) from birds. J Parasitol 2003; 9: 809-13.

[11] Ryan U. Cryptosporidium in birds, fish and amphibians. Exp Parasitol 2010; 124: 113-20.

[12] Morgan RUM, Monis P, Possenti A, Crisanti A, Spano F. Cloning and phylogenetic analysis of the ribosomal internal transcribed spacer-1 (ITS1) of Cryptosporidium wrairi and its relationship to $C$. parvum genotypes. Parassitologia 2001; 43: 159-63.

[13] Zhou L, Kassa H, Tiscler L, Xiao L. Host-adapted Cryptosporidium spp. in Canada geese (Branta canadensis). Appl Environ Microbiol 2004; 70: 4211-5.

[14] Ng J, Pavlasek I, Ryan U. Identification of novel Cryptosporidium genotypes from avian hosts. Appl Environ Microbiol 2006; 72: 548-53.

[15] Fayer R. Taxonomy and species delimitation in Cryptosporidium. Exp Parasitol 2010; 124: 90-7.

[16] Xiao L, Sulaiman IM, Ryan UM, Host adaptation and host-parasite co-evolution in Cryptosporidium: implications for taxonomy and public health. Int J Parasitol 2002; 32: 1773-85.

[17] Graczyk TK, Cranfield MR, Fayer R, Anderson MS. Viability and infectivity of Cryptosporidium parvum oocysts are retained upon intestinal passage though a refratory avian host. Appl Environ Microbiol 1996; 62: 3234-7.

[18] Graczyk TK, Fayer R, Trout JM, et al. Cysts Giardia and infections Cryptosporidium parvum oocysts in the feces of migratory Canada Geese (Branta canadensis). Appl Environ Microbiol 1998; 64: 2736-8.

[19] Nakamura AA, Simões DC, Antunes RG. Silva Da DC, Meireles, MV. Molecular characterization of Cryptosporidium spp. from fecal samples of birds kept in captivity in Brazil. Vet Parasitol 2009; 166 47-51

[20] Quah JX, Ambu S, Lim YAL, Mahdy MAK, Mak JW. Molecular identification of Cryptosporidium parvum from avian hosts. Parasitol 2011; 138: 573-7.

[21] Sevá AP, Funada MR, Richtzenhain C, et al. Genotyping of Cryptosporidium spp. from free-living wild birds from Brazil. Vet Parasitol 2011; 175: 27-32.

[22] Huber F, Silva Da S, Bomfim TCB, Teixeira KRS, Bello AR. Genotypic characterization and phylogenetic analysis of Cryptosporidium sp. from domestic animals in Brazil. Vet Parasitol 2007; 150: 65-74.

[23] Gomes RS, Huber F, Bomfim TCB. Cryptosporidium spp. parasitize exotic birds that are commercialized in markets, commercial aviaries, and pet shops. Parasitol Res 2012; 110: 136370 .

[24] Huber F, Bomfim TCB, Gomes RS. Comparation beteween natural infection by Cryptosporidium sp., Giardia sp. in dogs in two living situations in the West Zone of the city of Rio de Janeiro. Vet Parasitol 2005; 130: 69-72.

[25] Xiao L, Morgan UM, Limor J, et al. Genetic Diversity within Cryptosporidium parvum and related Cryptosporidium species. Appl Environ Microbiol 1999; 65: 3386-91.

[26] Xiao L, Altaf AL, Jiang J. Detection and differentiation of Cryptosporidium oocysts in water by PCR-RFLP. In: Spencer, JFT, Spencer ALR, Eds. Public Health Microbiology: Methods and Protocols. Totowana: Humana Press 2004; pp. 163-76.

[27] Xiao L, Feng Y. Zoonotic cryptosporidiosis. FEMS Immunol Med Microbiol 2004; 52: 309-23.

[28] Wang R, Jiana F, Suna Y, et al. Large-scale survey of Cryptosporidium spp. in chickens and Pekin ducks (Anas platyrhynchos) in Henan, China: prevalence and molecular characterization. Avian Pathol 2011; 39: 447-51.

[29] Lindsay DS, Blagburn BL, Hoerr FJ. Small intestinal cryptosporidiosis in cockatiels associated with Cryptosporidium baileyi-like oocysts. Avian Dis 1990; 34: 791-3. 
[30] Hoer FJ, Current WL, Haynes TB. Fatal cryptosporidiosis in quail. Avian Dis $1986 ; 30: 421-3$.

[31] Antunes RG, Simões DC, Nakamura AA, Meireles MV. Natural Infection with Cryptosporidium galli in Canaries (Serinus canaria), in a cockatiel (Nymphicus hollandicus), and in Lesser Seed-Finches (Oryzoborus angolensis) from Brazil. Avian Dis $2008 ; 52$ : 702-5.
[32] Amer S, Wang C, He H. First detection of Cryptosporidium baileyi in Ruddy Shelduck (Tadorna ferruginea) in China. J Vet Med Sci 2010; 72: 935-8.

[33] Majewska AC, Graczyk TK, Slodkowicz-Kowalska A. The role of free-ranging, captive, and domestic birds of Western Poland in environmental contamination with Cryptosporidium parvum oocysts and Giardia lamblia cysts. Parasitol Res 2009; 104: 10939.

(C) Bomfim et al.; Licensee Bentham Open.

This is an open access article licensed under the terms of the Creative Commons Attribution Non-Commercial License (http://creativecommons.org/licenses/by-nc/3.0/) which permits unrestricted, non-commercial use, distribution and reproduction in any medium, provided the work is properly cited. 